\title{
TRACE V5 CODE APPLICATION DVI LINE BREAK LOCA USING ATLAS FACILITY
}

\author{
FABIO VERONESE $^{1 *}$ and TOMASZ KOZLOWSK ${ }^{2}$ \\ ${ }^{1}$ Università di Pisa, Pisa, Italy \\ ${ }^{2}$ University of Illinois, Urbana-Champaign, USA \\ "Corresponding author. E-mail : fabio.veronese@dimnp.unipi.it
}

Received May 23, 2012

The object of this work is the validation and assessment of the TRACE v5.0 code using the scaled test ATLAS $^{1}$ facility in the context of a DVI ${ }^{2}$ line break. In particular, the experiment selected models the $50 \%, 6$-inch break of a DVI line. The same experiment was also adopted as a reference test in the ISP-50 ${ }^{3}$. The ISP-50 was proposed to, and accepted by, the OECD/NEA/CSNI due to its technical importance in the development of a best-estimate of safety analysis methodology for DVI line break accidents. In particular, the behavior of the two-phase flow in the upper annulus downcomer was expected to be complicated. What resulted was the need for relevant models to be implemented into safety analysis codes, in order to predict these thermal hydraulic phenomena correctly.

KEYWORDS : TRACE, ISP-50, DVI Line Break, ATLAS Facility, Loop Seal Clearing

\section{INTRODUCTION}

In some advanced nuclear reactors ${ }^{4}$, such as in the Korean APR1400, (Generation III and III+) the DVI is employed instead of the Cold Leg Injection (CLI) as an accident mitigation strategy. Since the thermal-hydraulics phenomena that come into play are different, especially the two-phase flow in the upper annulus downcomer, relevant models need to be implemented into safety analysis codes in order to correctly predict these thermal-hydraulics phenomena. For this reason, and also to increase the knowledge of the phenomena in play, the integral test ATLAS facility was built by the KAERI ${ }^{5}$ in 2005 . After several experimental campaigns on various types of rupture of the DVI line [1], the experiment SB-DVI-09 was chosen by the OECD/NEA/OCSI in 2008, as a reference test for the $50^{\text {th }}$ International Standard Problem (ISP-50) [2]. The test is a 50\%, 6-inch DVI break line, and it is used in this research for the validation and assessment of TRACE V5.0 Patch 2 with the objective of establishing its capability and limitations in the simulation of a DVI line break LOCA ${ }^{6}$.

\footnotetext{
${ }^{1}$ Advanced Thermal-hydraulic Test Loop for Accident Simulation

${ }^{2}$ Direct Vessel Injection

${ }^{3}$ International Standard Problem

${ }^{4}$ AP600, AP1000 and VVER-1000

${ }^{5}$ Korea Atomic Energy Research Institute

${ }^{6}$ Loss Of Coolant Accident
}

\section{FACILITY DESCRIPTION}

The ATLAS facility has 2 loops, 4 cold legs and 2 hot legs as the reference APR1400 reactor, and it is designed according to the scaling method suggested by Ishii and Kataoka [3] to simulate the various test scenarios as realistically as possible. In particular, it is a half-height and 1/288-volume scaled test facility and the time for the scaled model is $\sqrt{2}$ times faster than the prototypical time. According to the APR1400 geometry, the ATLAS fluid system consists of:

- a primary system (PS);

- a secondary system (SS);

- a Safety Injection System (SIS);

- a break simulating system;

- a containment simulating system;

- an auxiliary system.

The full description of the facility is described in the reports [4] and [5].

The break simulation system consists of a quick opening valve, a break nozzle, a case holding the break nozzle and the instrumentation (Figure 1). It is manufactured to have a scaled break flow during the test. The containment simulating system has a function of collecting the break flow and maintaining a specified back-pressure in order to simulate the containment. The schematic of the ATLAS facility for the actual DVI line break tests is showed in Figure 2. 


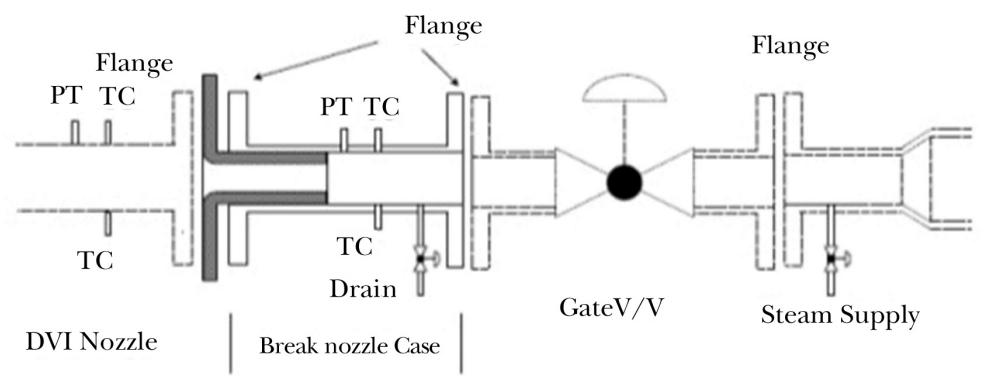

Fig. 1. Configuration of the Break Simulation System for the DVI Line Break Tests [4].

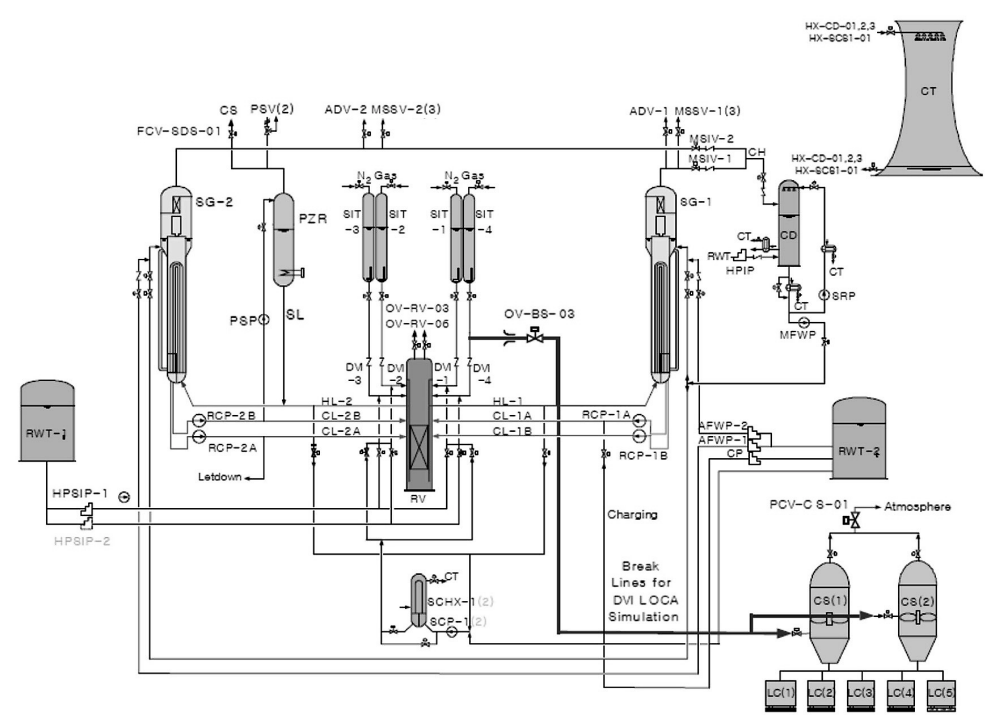

Fig. 2. Schematics of the ATLAS for the DVI Line Break Tests [4].

\section{EXPERIMENT DESCRIPTION}

The ISP-50 test on a 50\% DVI line break was performed in accordance with the test procedure described in the test specifications [6] and [7]. The initial and the boundary conditions for the present test were determined based on the calculated sequence of events of the DVI line break for the APR1400, (see Table 1).

Since the test was performed at full pressure, the pressure set points for actuation of major components were preserved as they occur in the reference plant.. The temperature distribution along the primary loop was also maintained at levels equivalent to the reference plant. Since the ATLAS has a maximum power capacity of $8 \%$ of the scaled full power, the secondary pressure of the ATLAS was slightly reduced to obtain a steady-state condition of $8 \%$ power level. The safety injection flow to the broken DVI-4 nozzle was not credited to obtain the minimum injection flow to the core. In addition, one train (two SIPs) was assumed to be disabled, so the safety injection flow by the SIP was provided only through the DVI-2 nozzle, opposite to the broken DVI-4 nozzle. For the core power, a conservative 1973 ANS decay heat curve with a 1.2 multiplication factor was used in the transient calculation, with a non-uniform cosine axial power distribution. In the DVI line break, the containment back-pressure did not affect the progression of this transient, because a choking condition was maintained throughout the transient. Therefore, the containment back-pressure was not an important control parameter.

After a steady-state condition was achieved, the system was maintained for more than 10 minutes, and the transient test was commenced. First, data logging was initiated to log all measurement points in a steady-state condition. After the initial data logging was completed for about $200 \mathrm{~s}$, the DVI line break test was initiated by opening a quick-opening break valve. When the pressurizer reached a specified pressure of $10.72 \mathrm{MPa}$, the low pressure (LPP) signal was automatically generated by embedded control logic. The heaters of the pressurizer, and all tracing heaters in the primary system, were tripped at the time of the LPP signal. The RCPs were automatically tripped with a time delay of $0.35 \mathrm{~s}$ after the LPP signal. The main steam and the main feed-water (FW) lines were isolated with a time delay of $0.1 \mathrm{~s}$ and $7.1 \mathrm{~s}$ after the LPP signal, respectively. Operation of the SIP was triggered by the LPP signal with 
Table 1. Comparison between Reference Reactor and ATLAS Facility Sequences.

\begin{tabular}{|c|c|c|c|}
\hline Events & $\begin{array}{r}\text { APR1400 } \\
\text { (time, sec) }\end{array}$ & $\begin{array}{c}\text { ATLAS } \\
\text { (time, sec) }\end{array}$ & Description \\
\hline Break open & 0 & 0 & \\
\hline Low pressurizer pressure trip (LPP) & 28.6=LPP & & If pressurizer pressure $<10.72 \mathrm{MPa}$ \\
\hline Pressurizer heater trip & $\mathrm{LPP}+0.0 \mathrm{sec}$ & $\mathrm{LPP}+0.0 \mathrm{sec}$ & \\
\hline Reactor scram \& RCP trip & $\mathrm{LPP}+0.5 \mathrm{sec}$ & $\mathrm{LPP}+0.35 \mathrm{sec}$ & \\
\hline Turbine isolation & $\mathrm{LPP}+0.1 \mathrm{sec}$ & $\mathrm{LPP}+0.07 \mathrm{sec}$ & \\
\hline Main FW isolation & $\mathrm{LPP}+10 \mathrm{sec}$ & $\mathrm{LPP}+7.07 \mathrm{sec}$ & \\
\hline Safety injection pump start & $\mathrm{LPP}+40 \mathrm{sec}$ & $\mathrm{LPP}+28.28 \mathrm{sec}$ & \\
\hline Low upper down-comer pressure trip (LUDP) & LUDP & LUDP & If DC pressure $<4.03 \mathrm{MPa}$ \\
\hline Safety injection tank (SIT) start & LUDP+0.0 sec & LUDP+0.0 sec & \\
\hline Low flow turndown of the SIT & & & $\begin{array}{l}\text { If water level of the SIT is less than a } \\
\text { specified set point }\end{array}$ \\
\hline
\end{tabular}

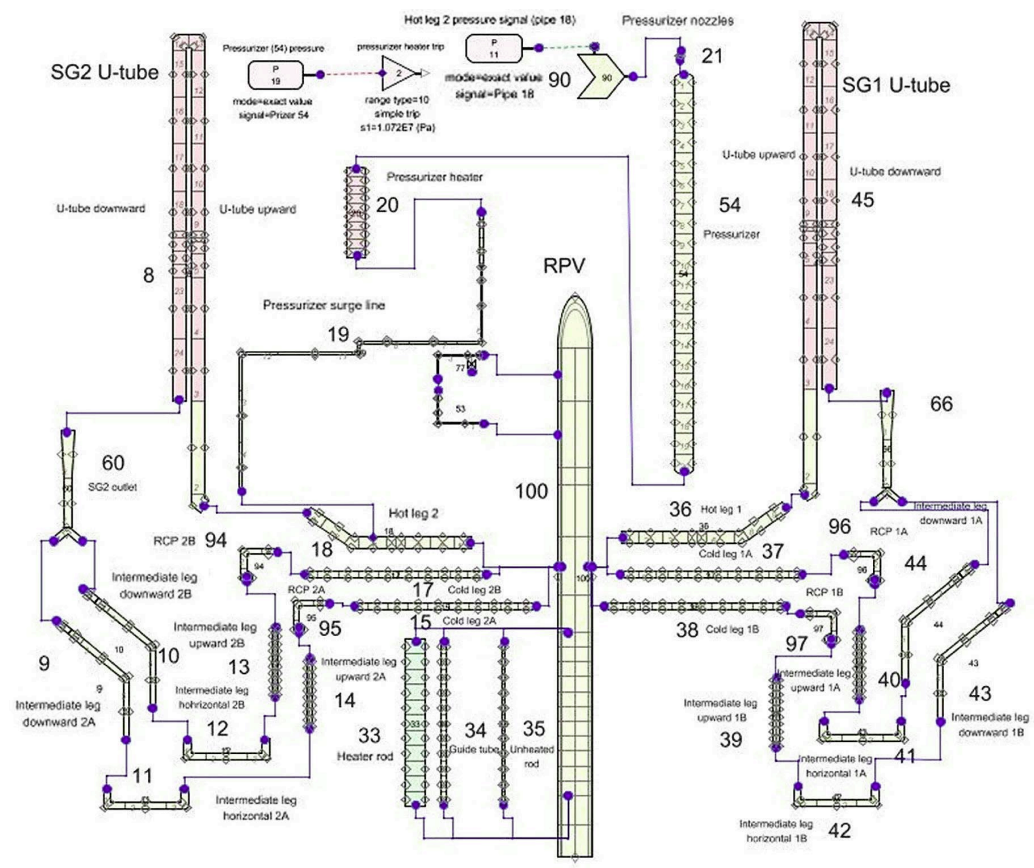

Fig. 3. Primary System

a time delay of $28.3 \mathrm{~s}$. When the downcomer pressure of the RPV became lower than the specified pressure of 4.03 MPa, the SIT started to deliver the high safety injection flow to the RPV by fully opening the flow control valve. When the water level of the SIT reached a specified set point, the stem of the flow control valve was lowered to a specified position in order to supply a required low injection flow rate. When the water level of the SIT decreased to a specified empty set point, the flow control valve was fully closed to prevent the nitrogen gas, present in the upper part, from being injected into the RCS.

\section{TRACE MODEL AND CALCULATION}

The post-test calculations have been performed using the NRC code TRACE V5.0 Patch 2 on a current generation $3.00 \mathrm{GHz}$ Intel CPU with Windows 7 operating system. The total CPU time for transient calculation is $25000 \mathrm{~s}$, while the minimum time step used is $0.001 \mathrm{~s}$.

The ATLAS facility model used for the calculation is shown on Figure 3 to Figure 6. The PS is shown on Figure 3, while the SS is shown on Figure 5. The break line and the ECCS nodalization are shown on Figure 4 


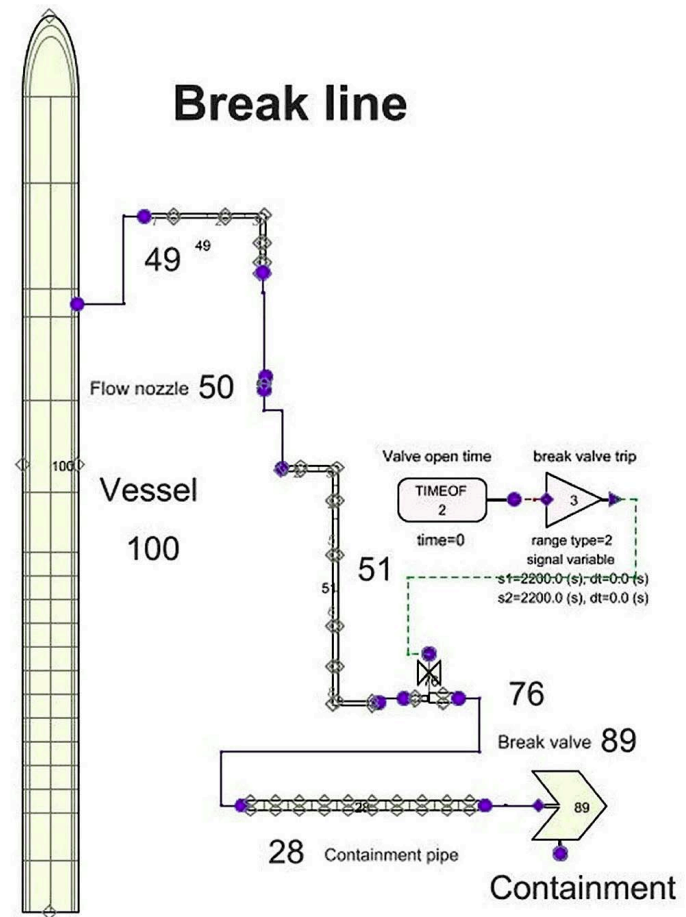

Fig. 4. Break Line

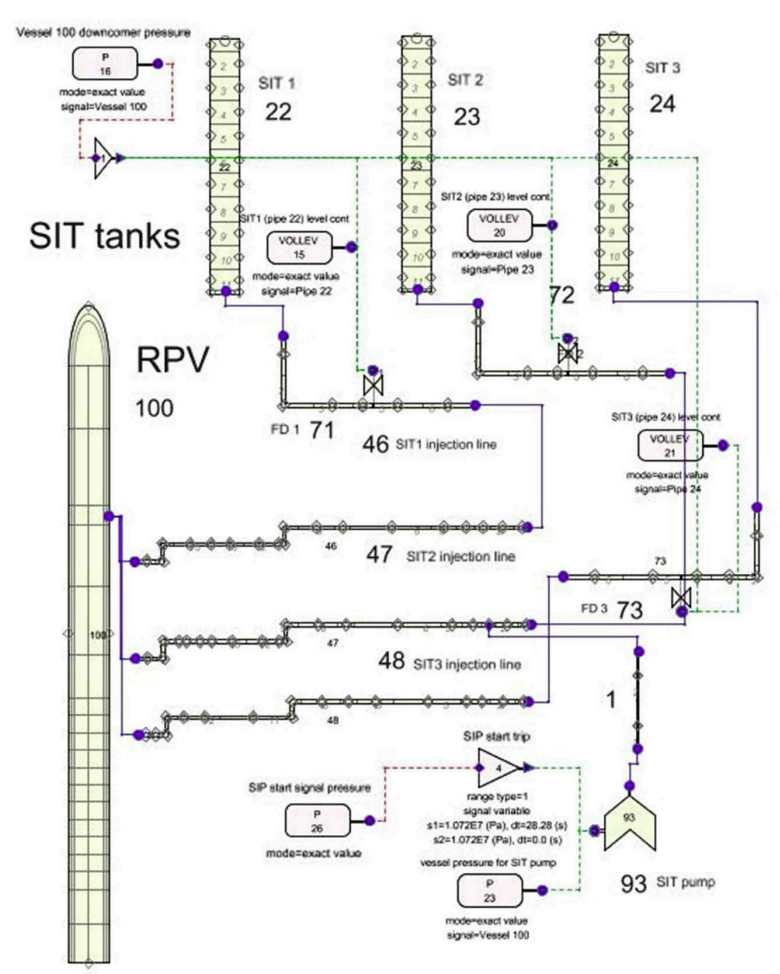

Fig. 6. ECCS

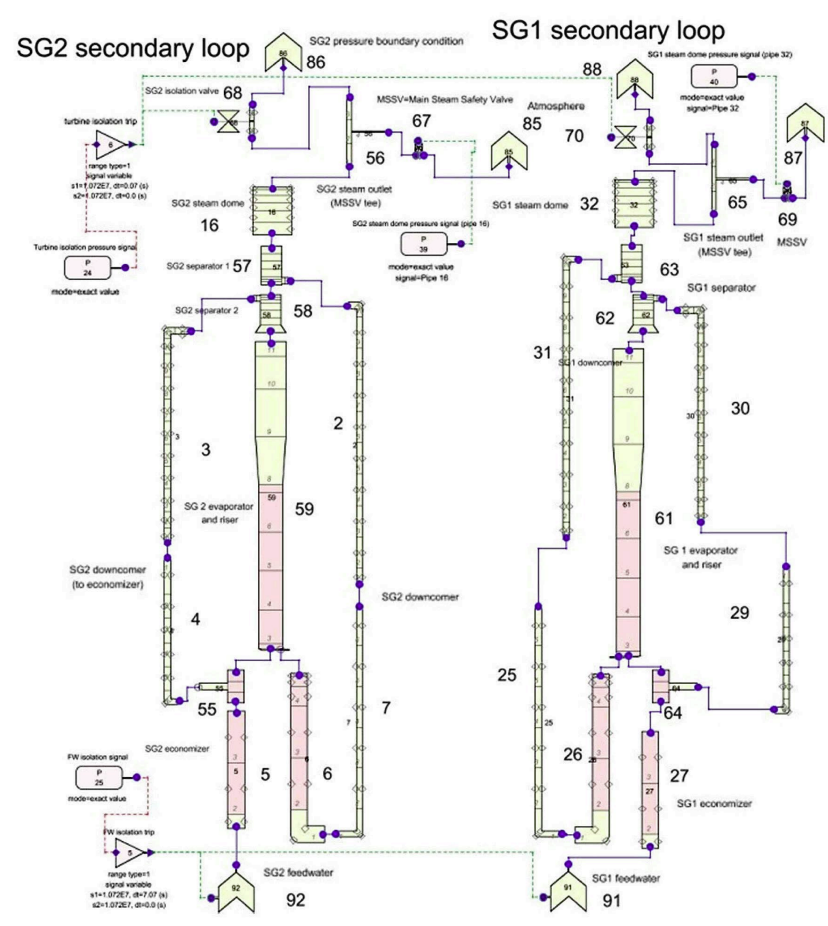

Fig. 5. Secondary System

and Figure 6, respectively.

The TRACE ATLAS model contains a total of 863 volumes (342 for the vessel, 521 for the remaining components) and 97 junctions (excluding internal junctions between volumes belonging to the same component). There are four heat structures, one heater (core) rod, two SGs exchange heat walls and one pressurizer heater. The Reactor Pressure Vessel (RPV) is a 3D component with 19 axial cells, 3 radial cells, and 6 azimuthal cells, where the DC is the external radial ring of the RPV. In all the 1D PIPE components the K-factors are set to 0.4 and 0.32 for every $45^{\circ}$ and $15^{\circ}$ elbows, respectively. In the RPV, $\mathrm{K}$-factor is set to 10 in the flow area between Level 1 and Level 2, corresponding to the flow area between lower plenum and bottom of the core. the CCFL model has been introduced In both the SG U-tubes.

\subsection{Break Line}

The break line is composed of 4 pipes and 1 valve, composed of 20 volumes. The containment component is simulated imposing the pressure boundary conditions during the transient (Figure 4). Abrupt area change and choking flow is activated for the break nozzle inlet and outlet edge, as well as for the edge facing the containment component. This pipe also has K-factor $=10$ distributed in every cell edge in order to obtain correct pressure drop along the break line (fitted to experimental data). The default choked flow model was used in the input.

\subsection{Emergency Core Cooling System (ECCS)}

The ECCS is composed of 165 volumes (Figure 6). Every SIT tank is a pipe composed of 12 cells, while 
Table 2. Measured and Calculated Initial Conditions.

\begin{tabular}{|c|c|c|c|}
\hline Variables & Experiment & Calculation & Error* \\
\hline \multicolumn{4}{|l|}{ Primary system } \\
\hline Core power [W] & $1.636 \mathrm{E}+06$ & $1.636 \mathrm{E}+06$ & $0.0 \%$ \\
\hline Pressure $[\mathrm{Pa}]$ & $1.56 \mathrm{E}+07$ & $1.534 \mathrm{E}+07$ & $1.7 \%$ \\
\hline Core inlet temp [K] & 563.2 & 562.9 & $0.1 \%$ \\
\hline Core exit temp [K] & 598.2 & 598.3 & $0.0 \%$ \\
\hline CL flow rate $[\mathrm{kg} / \mathrm{s}]$ & 2.2 & 1.958 & $11.0 \%$ \\
\hline Bypass flow [kg/s] & 0 & 0 & $0.0 \%$ \\
\hline PZR level [m] & 3.32 & 3.23 & $2.6 \%$ \\
\hline RCP speed [rpm] & 18.7 & 21.5 & $14.9 \%$ \\
\hline \multicolumn{4}{|l|}{ Secondary system } \\
\hline Pressure $[\mathrm{Pa}]$ & $7.83 \mathrm{E}+06$ & $7.83 \mathrm{E}+06$ & $0.0 \%$ \\
\hline Steam temperature $[\mathrm{K}]$ & 566.2 & 566.7 & $0.1 \%$ \\
\hline FW temperature $[\mathrm{K}]$ & 505.9 & 508.0 & $0.4 \%$ \\
\hline FW flow $(\mathrm{ECO})[\mathrm{kg} / \mathrm{s}]$ & $0.431 / 0.435$ & $0.473 / 0.473$ & $9.7 / 8.7 \%$ \\
\hline FW flow (DC) $[\mathrm{kg} / \mathrm{s}]$ & 0 & 0 & $0.0 \%$ \\
\hline SG level [m] & $2.03 / 1.97$ & $3.44 / 3.43$ & $69.5 / 74.1 \%$ \\
\hline Heat removal per each SG $[\mathrm{kW}]$ & $7.80 \mathrm{E}+02 * *$ & $8.17 \mathrm{E}+02$ & $4.8 \%$ \\
\hline \multicolumn{4}{|l|}{ ECCS } \\
\hline SIT pressure $[\mathrm{Pa}]$ & $4.23 \mathrm{E}+06$ & $4.21 \mathrm{E}+06$ & $0.5 \%$ \\
\hline SIT temperature $[\mathrm{K}]$ & 323.15 & 323.42 & $0.1 \%$ \\
\hline SIT level [\%] & 95 & 95 & $0.0 \%$ \\
\hline RWT temperature [K] & 323.15 & 323.15 & $0.0 \%$ \\
\hline \multicolumn{4}{|l|}{ Containment } \\
\hline Pressure $[\mathrm{Pa}]$ & $1.01 \mathrm{E}+05$ & $1.03 \mathrm{E}+05$ & $1.6 \%$ \\
\hline
\end{tabular}

* The absolute percentage difference between experiment and calculated values was determined using the following formula:

$\mid$ Error $|=| \frac{\mathrm{v}_{\text {cal }}-\mathrm{v}_{\exp }}{\mathrm{v}_{\exp }} \mid$

** From core power value and heat removal per each SG, the heat losses are valued $76 \mathrm{~kW}$

every SIT line is composed of 1 pipe and 1 valve component with 22 volumes each. Abrupt area change and choked flow option are activated in the connection with the vessel component, in the bottom of the SIT and in the valve stem.

\section{COMPARISON OF THE RESULTS}

Table 2 compares the initial conditions of the main quantities. The nominal steady-state conditions are simu- lated by a 2000 seconds "null transient" calculation. The largest disagreements are for the flow rates, the water levels and the heat losses. The model flow rate in the primary system is lower in order to obtain a correct fluid temperature, which was measured more precisely than the mass flow rates ${ }^{7}$. This also explains the differences in the RCP speeds. The higher FW flow rate entering the SG

\footnotetext{
${ }^{7}$ Based on communication with ATLAS experimentalists, the mass flow uncertainty reaches values of $10 \%$
} 
Table 3. Measured and Calculated Occurrences

\begin{tabular}{|c|c|c|c|}
\hline Events & DAS $^{8}$ time (s) & TRACE time (s) & Remarks \\
\hline Data logging starts & -203.0 & -2200.0 & \\
\hline Break valve open & 0.0 & 0.0 & \\
\hline MMSV of SG-2 open ( $1^{\text {st }}$ opening $)$ & 24.0 & 41.1 & PT-SGSD2-01>8.1 MPa \\
\hline MMSV of SG-1 open ( $1^{\text {st }}$ opening $)$ & 24.0 & 41.1 & PT-SGSD1-01>8.1 MPa \\
\hline Low pressurizer pressure trip (LLP) & 25.0 & 38.08 & PT-SGSD1-01<10.7214 MPa \\
\hline Pressurizer heater OFF & 25.0 & 38.08 & $\mathrm{LPP}+0.0 \mathrm{sec}$ \\
\hline Main steam isolation & 25.0 & 38.08 & $\mathrm{LPP}+0.1 \mathrm{sec}$ \\
\hline RCPs trip & 25.0 & 38.08 & $\mathrm{LPP}+0.35 \mathrm{sec}$ \\
\hline Main feed water isolation & 32.0 & 44.09 & $\mathrm{LPP}+7.0 \mathrm{sec}$ \\
\hline Core power stars to decay & 33.0 & 32.00 & \\
\hline SIP-2 injection & 54.0 & 66.14 & \\
\hline MSSV of SG-2 open $\left(2^{\text {nd }}\right.$ opening $)$ & 57.0 & 64.1 & PT-SGSD2-01>8.1 MPa \\
\hline MSSV of SG-1 open $\left(2^{\text {nd }}\right.$ opening $)$ & 62.0 & 68.2 & PT-SGSD1-01>8.1 MPa \\
\hline MSSV of SG-2 open ( $3^{\text {rd }}$ opening) & 113.0 & 99.2 & PT-SGSD2-01>8.1 MPa \\
\hline MSSV of SG-1 open ( $3^{\text {rd }}$ opening) & 118.0 & 101.2 & PT-SGSD1-01>8.1 MPa \\
\hline $1^{\text {st }}$ loop seal clearing occurs & 190.0 & 423 & Only in loop $1 \mathrm{~A} / 1 \mathrm{~B}$ \\
\hline SIT actuation (high flow) & 468.0 & 435.89 & PT-DC-01<4.03 MPa \\
\hline $2^{\text {nd }}$ loop seal clearing occurs & 1236.0 & - & Loop 2B \\
\hline SIT low flow conversion & - & - & Did not occur \\
\hline Test stops & 2933.0 & 3300 & \\
\hline
\end{tabular}

economizer is needed to simulate the heat losses in the primary and secondary circuit, which are not explicitly simulated in this model and cannot be neglected in the scaled test facility. This also explains the disagreements in the heat removal from each SG: it must be higher in order to maintain the temperature closer to the experimental value. The SG water levels show significant discrepancies since the SG model geometry had to be modified to obtain better model convergence.

Timing of the main transient events is summarized in Table 3. All the events related to the SIS actuation occur later in the TRACE model than in the experiment, until the SIP-2 injection starts. Due to the difference in pressure trends in the PRZ, the SIT actuation occurs earlier in the model. This is brought on by the fact that the PRZ controls all the safety injection trips in the model and in the ATLAS facility.

\footnotetext{
${ }^{8}$ Data Acquisition System
}

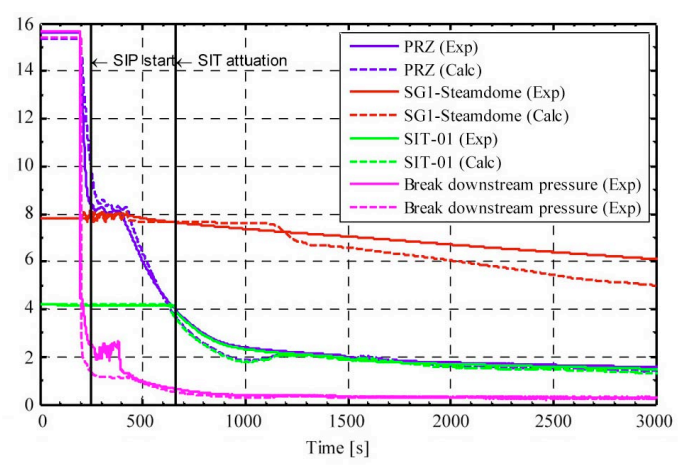

Fig. 7. Main Pressure Trends in the Primary and Secondary Circuit.

This is easily understandable from Figure 7 where the main pressure trends in the facility are plotted. The pressure in the model is higher than in the experiment for the initial 500 seconds after which time the trend reverses. The difference in the pressure trend also affects the differences in the break accumulate mass (Figure 10) and the active SIP flow rate (Figure 11). In fact, since less water flows 


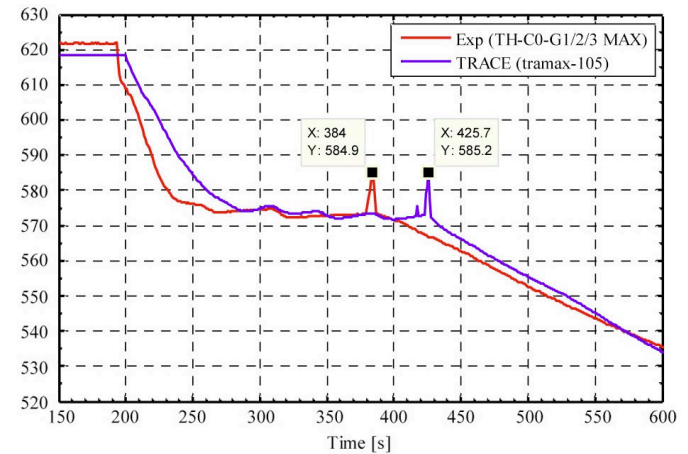

Fig. 8. Enlargement of the Max Active Core Region Temperature.

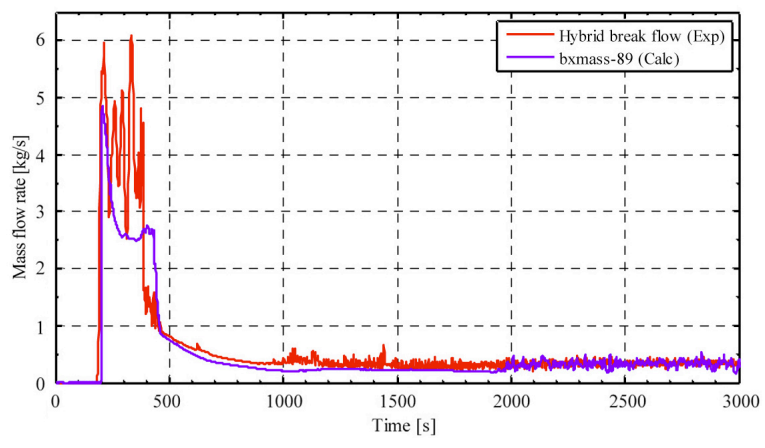

Fig. 9. Break Mass Flow.

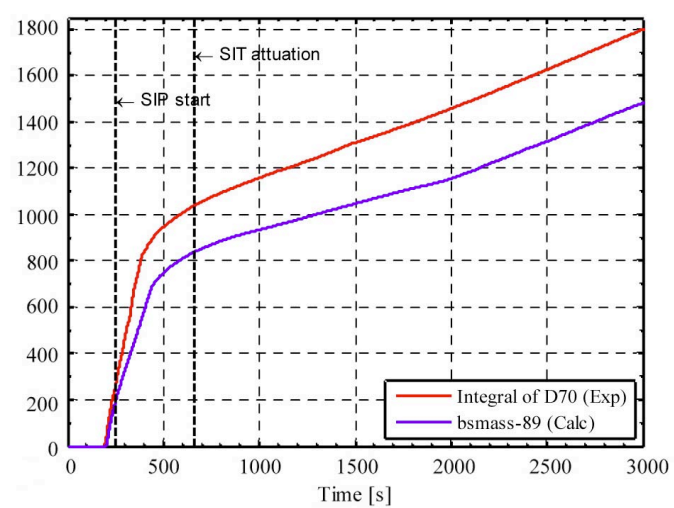

Fig. 10. Break Water Accumulated Mass [kg].

out through the break (Figure 9) the pressure decreases less in the first $500 \mathrm{~s}$ of the transient. On the contrary, in the last part of the transient more water is injected into the model by the SIP because the mass flow is inversely proportional to the PS pressure (centrifugal pump). As a direct consequence, there is a slight disagreement in the primary total mass: in the TRACE model it retains more water in the primary system.

Despite of the above listed differences, the TRACE model is able to predict the heating up if the core. The calculated value is in good agreement with the experiment but it occurs later (see Figure 8). The delay in the heat up

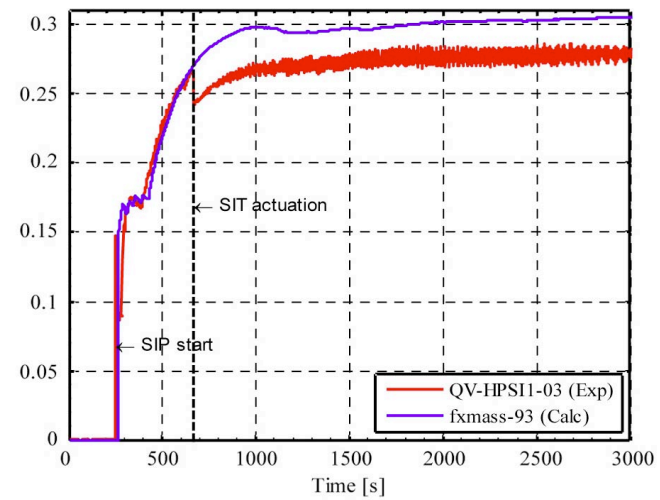

Fig. 11. SIP Flow Rate $[\mathrm{kg} / \mathrm{s}]$.

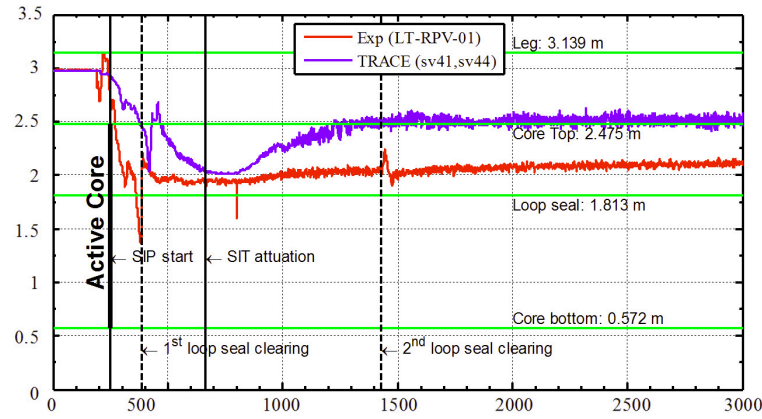

Fig. 12. Measured vs. TRACE Collapsed Water Level of Core Region

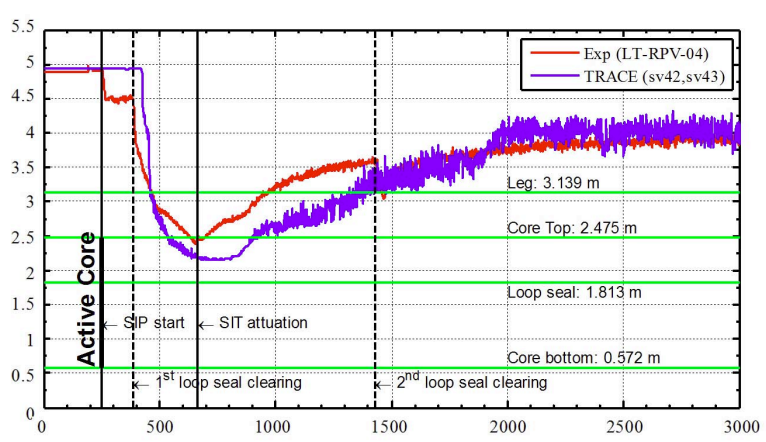

Fig. 13. Measured vs. TRACE Collapsed Water Level of the Downcomer

is again due to the different pressure trend in the PS (Figure 7).

Also the liquid levels in the DC and in the core are well predicted (Figure 12 and Figure 13). In the experiment the core liquid level remains around 2 meters, leaving the core partially uncovered, while in the TRACE model the core remains covered except for a short period. However, the level trend in the DC is better modeled (Figure 13). There is only a little delay in the rise of the level in the TRACE model due to the delay in the SIT activation. The liquid level disagreements are due to lower mass flow rate at the break, which directly affects the primary 

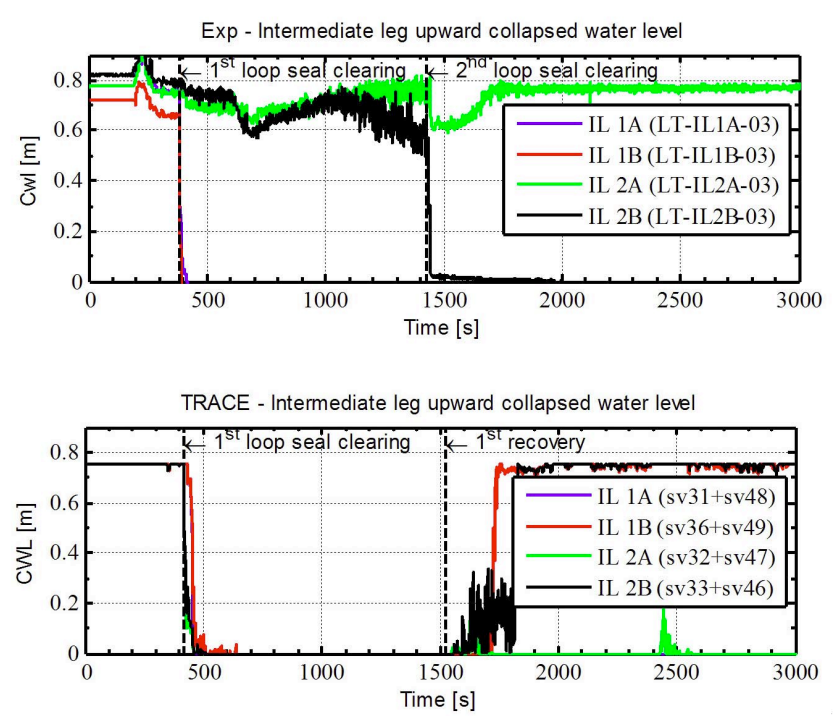

Fig. 14. Intermediate Leg Upward CWL

depressurization and occurrence of the main phenomena.

The TRACE model is able to predict part of the loop seal clearing phenomenon and its effects, such as the increase in the core level and the corresponding decrease in the downcomer level when loop seal clearing occurs. This normally happens in the reactors using CLI safety features [8] and the same is inferred to happen in this test. While in the model the $1^{\text {st }}$ loop seal clearing is perfectly noticeable in the collapsed water level trend in the core active region (the sharply level drop in Figure 12), the same does not happen for the $2^{\text {nd }}$ loop seal clearing.

Another evidence of the TRACE model deficiency in the loop seal simulation is showed in Figure 14. While in the experiment the $1^{\text {st }}$ loop seal clearing occurs in loop 1 and only after some seconds is followed by a $2^{\text {nd }}$ loop seal clearing in branch B of loop 2, in the TRACE model the loop seal clearing occurs in all the loops at the same time (around 420 seconds). Furthermore, the level in leg $1 \mathrm{~B}$ rises again, followed by leg $2 \mathrm{~B}$, which is the opposite of the measured trend.

The disagreement is probably due to the Counter Current Flow Limiting (CCFL) model, which is activated in the primary circuit but only in the Steam generator Utubes. and to the mismatch in the primary system total mass balance and how water is distributed in the system. The CCFL is an important phenomenon every time there are liquids and vapor flowing in a direction counter to the actual current in a vertical pipe. The asymmetry in the collapsed water level model trend could be attributable to some DC bypass flows present in the real experiment that are not modeled in the TRACE model. As mentioned earlier, the TRACE model predicts the occurrence of loop seal clearing in all the legs at the same instant, while in the experiment they occur first in both the legs 1 and later only in the leg $2 \mathrm{~B}$

\section{CONCLUSIONS}

The study of the $50 \%$ (6-inch) DVI break (experiment SB-DVI-09), reference test for the ISP-50, was used for the verification of the best-estimate thermal-hydraulics code TRACE.

Generally, the code is capable of calculating the main phenomena of the experiment. Exceptions can be seen in instances where the model fails to simulate properly the $2^{\text {nd }}$ loop seal clearing, while at the same time it is perfectly able to determine the core heat up. Despite some deficiencies of the model, the calculated results show agreement with the measured data. It should be emphasized that the differences between the experiment and TRACE results, in case of the loop seal clearing, are not a code limitation. Rather, it is a modeling problem and further investigations are required to study such phenomena, especially to take into account the CCFL phenomenon in all the primary circuit (e.g. in the core) and not only in the SG U-tube components.

\section{REFERENCES}

[1] Kim, Y. S. et al, "Commissioning of the ATLAS ThermalHydraulic Integral Test Facility", Annals of Nuclear Energy, 35, 1791 (2008)

[2 ] K. Y. Choi et al., "Final IntegrationReport of International Standard Problem N50”, NEA/CSNI/R(2012)6, Feb. 2012

[3 ] Kataoka, M. Ishii and I., "Similarity Analysis and Scaling Criteria for LWRs Under Single Phase and Two-Phase Natural Circulation", NUREG/CR-3267, Argonne National Laboratory, ANL-83-32, 1983

[4] Kyoung-Ho K, "ATLAS Facility and Instrumentation Description Report”, KAERI/TR-3779/2009, June 2009

[ 5 ] K. H. Kang et al., "Detailed Description Report of ATLAS Facility and Instrumentation", KAERI/TR-4316/2011

[6] KyoungHo K, "ATLAS Facility and Instrumentation Description Report", KAERI/TR-3779/2009

[ 7 ] K. Y. Choi et al., "ISP-50 Specifications for a Direct Vessel Injection Line Break Test with the ATLAS", KAERI/TR3778/2009

[ 8 ] J. Liebert, R. Emmerling, "UPTF experiment Flow phenomena during full-scale loop seal clearing of a PWR" 